\section{Health situation in former communist bloc is dire, says Unicef}

James Ciment New York

Marking the tenth anniversary of the fall of the Berlin Wall, the United Nations Children's Fund (Unicef) has issued a report on the social ramifications of the transition to market economies in the former communist bloc.

The report, After the Fall: the Human Impact of Ten Years of Transition, states that women and children have suffered especially hard. Although the report chronicles a host of economic and social problems, its findings on health are particularly disturbing, especially on

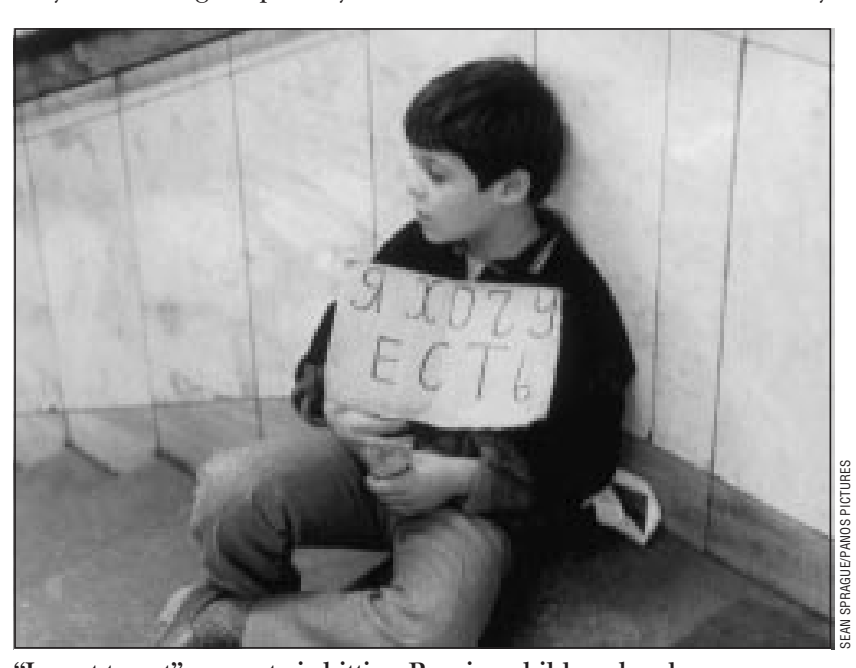

"I want to eat"-poverty is hitting Russian children hard

the reappearance of so called "poverty diseases."

The number of cases of diphtheria in Russia and Ukraine rose from about 1900 cases in 1990 to 43000 in 1998 . Poliomyelitis, which had been virtually eliminated in the former Soviet Union, has reappeared in the Central Asian Republics and Ukraine.

Tuberculosis is also on the rise in the western parts of the former Soviet Union, with children accounting for over $10 \%$ of new cases. Cases of sexually

\section{chex}

\section{Royal college launches new effectiveness unit}

Gavin Yamey BMJ

The Royal College of Physicians of London has launched a clinical effectiveness and evaluation unit, taking the place of its previous research unit, to focus on clinical audit and national clinical guidelines for England and Wales.

The unit's core programme targets six major health issues, which are at the centre of the government's national healthcare agenda-coronary heart disease, stroke, lung cancer,

diabetes, older people, and evidence based prescribing for older patients.

Recent projects have included national clinical guidelines for managing stroke and a clinical audit of the long term care of elderly people. Its national sentinel audit of stroke, which covered $80 \%$ of hospitals managing patients with stroke, found that hospitals that established stroke units were able to deliver better care (Journal of the Royal College of Physicians 1999;33:460-4).

Other aims of the unit are to devise and validate outcome indicators of patient management and methods for assessing whether best practice is being used effectively. It will also support the work of the National Institute of Clinical Excellence (NICE), such as in developing national service frameworks. transmitted diseases are increasing as well.

Syphilis, practically eliminated by 1990 , has re-emerged in the former Soviet Union, with some 221 cases per 100000 people in 1998, more than 100 times the average of the European Union.

Meanwhile, the number of cases of HIV infection in the western part of the former Soviet Union had climbed from 30000 in 1994 to 270000 by the end of 1998. "It is safe to say," the report argues, "that these areas now face an epidemic of HIV and AIDS."

There are several factors behind these disturbing trends, the report's authors conclude. Although some countries in the region have fared better than others in terms of health statistics, every single one has cut its spending on health care over the past 10 years.

Meanwhile, the despair caused by economic collapse has led to soaring drug misuse, alcoholism, injury, and suicide rates among young people. In the Czech Republic, for example, teenagers aged 15 to 19 were twice as likely to end their own lives in 1994 as they were in 1990.

Asked to cite any encouraging signs in the region, Patrick McCormick, a spokesperson for Unicef's Research Centre in Florence, which published the report, said, "there is a freedom now." But, he added, "children are paying too high a price for that freedom and they are not in a position to benefit from it."
Professor Sir Michael Rawlins, the institute's chairman, said at the unit launch: "NICE is in the business of promoting excellence in the NHS. It has a small core of staff, but it links to many other organisations. It is inevitable that NICE will want to form a collaborative partnership with the college."

Professor George Alberti, president of the royal college, said: "NICE has set itself a formidable agenda-but it is an essential part of the new, better focused NHS targeting inequalities in health. Our [clinical effectiveness and evaluation unit] will do all in its power to drive and accelerate this important programme. We hope that the funds will be available to allow the work to be done speedily and efficiently for the benefit of the health of the public."

\section{Call for greater care of elderly people in surgery}

\section{Zosia Kmietowicz London}

Elderly patients have their operations cancelled too often and should be given greater priority to prevent delays of more than 24 hours, according to the latest report from the national confidential enquiry into perioperative deaths (NCEPOD).

Nearly a fifth $(19 \%)$ of all operations in patients aged over 90 were delayed for nonmedical reasons or because of insufficient theatre time or "overbooked lists" in the 12 months to 31 March 1998.

As elderly people "do not tolerate repeated episodes of preoperative starvation, prolonged pain, sepsis or immobility" they should be given a high surgical priority, say the report's authors.

NCEPOD collects basic information on all patients who die within 30 days of a surgical procedure, and each year it reviews a sample of reported deaths in more detail. This year the review categories were patients aged 90 and over and children under 16 .

In general, the report recommends greater care when managing all elderly patients (not just those over 90) who require surgery, and it calls for more postoperative intensive care facilities. In particular, fluid intake and output immediately before and after surgery needs to be managed better to avoid possible adverse effects.

"Fluid management seems to assume less importance than drug monitoring in the UK, but it should have equal status," said Dr Cathy Sherry, clinical coordinator of the enquiry and consultant anaesthetist at the Northern General NHS Trust in Sheffield.

\section{Correction}

Drug resistant TB is spreading worldwide

An error occurred in this item by Janice Hopkins Tanne (6 November, p 1220). The first sentence should have read: "Tuberculosis that is resistant to the standard, four drug regimen has now been found in 104 countries, according to a report released last week in New York." 